\title{
PAPER
}

\section{Focused high frequency repetitive transcranial magnetic stimulation for localisation of the unexposed primary motor cortex during brain tumour surgery}

\author{
V Rohde, L Mayfrank, M Weinzierl, T Krings, J M Gilsbach
}

J Neurol Neurosurg Psychiatry 2003;74:1283-1287

See end of article for authors' affiliations

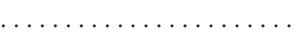

Correspondence to: Dr V Rohde, Department of Neurogurgery, University of Technology (RWTH) Aachen, Pauwelsstrasse 30, D-52057 Aachen, Germany; vrohde@ ukaachen.de

Received

17 October 2001

In final revised form

12 February 2003

Accepted 17 March 2003

\begin{abstract}
Objectives: To investigate if intraoperative focused high frequency repetitive transcranial magnetic stimulation (rTMS) can localise the primary motor cortex without exposure of the cortical surface.

Methods: A high frequency train $(357 \mathrm{~Hz})$ of four suprathreshold magnetic stimuli was delivered transcranially to the region of the rolandic area during brain tumour operations in 12 patients. To induce a focal magnetoelectric field, the flat figure of eight coil (outer diameter of each loop $7 \mathrm{~cm}$ ) was used. Motor evoked potentials (MEP) were recorded in eight muscles of the upper and lower contralateral extremities. The first stimulation site was $2.5 \mathrm{~cm}$ behind the bregma, the second site $2 \mathrm{~cm}$, and the third site $4 \mathrm{~cm}$ dorsal to the first stimulation site. If no MEP were obtainable, stimulation was repeated in anteroposterior direction at more laterally located sites. Using neuronavigation, each positive stimulation site was correlated with the underlying cortical anatomy.

Results: Stimulation was performed at a total of 42 sites (in two patients, maximum stimulation at the three initial sites failed to evoke a motor response). In four patients, MEP were obtained only from one stimulation site. This site exactly overlayed the primary motor cortex. In eight patients, MEP could be elicited from more than one stimulation site. In seven of the eight patients, the site from which MEP with peak amplitudes were elicited, corresponded to the primary motor cortex. In total, the primary motor cortex was correctly identified on the basis of electrophysiological findings in 11 of 12 patients (92\%). In two patients, only the more lateral stimulation sites permitted MEP recording.

Conclusion: Intraoperative focused rTMS is highly sensitive for localisation of the primary motor cortex. Focused rTMS as a localising instrument alleviates the need of motor cortex exposure and, thereby, can contribute to minimise the surgical approach to brain tumours in the rolandic area.
\end{abstract}

$\mathrm{N}$ on-invasive transcranial magnetic stimulation (TMS) of the motor cortex and recording of motor evoked potentials (MEP) was introduced into the clinical routine in $1985 .{ }^{1}$ As the short magnetoelectrical impulse activates pyramidal cells indirectly via interneurons, the elicited corticospinal volley mainly consists of indirect (I) waves. ${ }^{2}$ Narcotics and sedatives largely supress the electromyographic response in the target muscle by reduction of the descending I waves. ${ }^{3}$ Thus, TMS was almost exclusively used for the assessment of the descending motor pathways and for non-invasive localisation and somatotopic mapping of the praecentral gyrus in awake patients. ${ }^{4-8}$ Recent research work indicates that four suprathreshold, highly frequent repetitive transcranial magnetic stimuli (rTMS), elicit a sufficient number of I waves for $\alpha$ motoneuron activation and muscle contraction in anaesthesised humans. ${ }^{9-11}$ The neurosurgical therapy of intra-axial and extra-axial tumours in the rolandic area carries a high risk of postoperative motor deficits. For their avoidance, knowledge about the localisation of the praecentral gyrus during surgery is required. In times of minimalised surgical approaches, localising eloquent areas without exposure could be a desirable goal. It was the objective of this study to investigate if focused rTMS permits the intraoperative identification of the motor cortex without its exposure.

\section{METHODS}

Patients

After skin incision just before skull opening, focused rTMS was performed in 12 patients (eight men, four women, mean age 52 years) with a tumour in vicinity to the rolandic area. Eight tumours were located anterior and four tumours posterior to the central sulcus. The histological examination after tumour removal revealed meningioma in four cases, glioma in seven cases, and metastasis in one case. The technique of focused rTMS was explained to the patients preoperatively, all of whom gave their informed consent.

\section{Premedication and anaesthesia}

Oral medication with $7.5 \mathrm{mg}$ midazolam was given 60 minutes before induction of anaesthesia, which was accomplished with $2 \mathrm{mg} / \mathrm{kg}$ propofol, 0.1 to $0.2 \mu \mathrm{g} / \mathrm{kg}$ fentanyl and 0.1 to 0.2 $\mathrm{mg} / \mathrm{kg}$ mivacurium to facilitate endotracheal intubation and positioning for operation. Anaesthesia was maintained using a continuous infusion of $5 \mathrm{mg} / \mathrm{kg} / \mathrm{h}$ propofol and $60 \%$ nitrous oxide in oxygen. During the investigation, the cardiorespiratory parameters were kept constant.

\section{Focused high frequency rTMS}

The Magstim QuadroPulse (The Magstim Company Limited, Whitland, Great Britain) permits the delivery of a train of two to four monophasic magnetic stimuli with a maximum magnetic field of 2.5 T. Each stimulus has a duration of $100 \mu$ s. For intraoperative excitation of cortical structures, a train of four stimuli with an interstimulus interval of $2.8 \mathrm{~ms}$ was used, which, in our experience, proved to be most successful in generating recordable MEP in the target muscle. ${ }^{11}$ Three stimulation sites were used: The first stimulation site was $2.5 \mathrm{~cm}$ behind the bregma close to midline. The subsequent stimulation sites were about $2 \mathrm{~cm}$ ( $4.5 \mathrm{~cm}$ behind bregma) and $4 \mathrm{~cm}$

Abbreviations: rTMS, repetitive transcranial magnetic stimulation; MEP, motor evoked potentials 
Table 1 Demographic data and motor evoked potential (MEP) findings of 12 patients who underwent focused repetitive transcranial magnetic stimulation (rTMS) for mapping of the rolandic area during brain tumour surgery. The peak amplitudes are written in bold type. With the help of neuronavigation, the underlying cortical anatomy (supplementary motor area (SMA), precentral gyrus, postcentral gyrus) of each stimulation site was determined

\begin{tabular}{|c|c|c|c|c|c|c|}
\hline \multirow[b]{3}{*}{$\mathrm{N}$} & \multirow[b]{3}{*}{ Age $(y) / \operatorname{sex}$} & \multirow[b]{3}{*}{ Tumour } & \multirow[b]{3}{*}{ Location } & \multicolumn{3}{|c|}{$\begin{array}{l}\text { Maximum amplitude }(\mathrm{mV}) \text { of reproducible motor evoked } \\
\text { potentials (MEP) in relation to stimulation site } 1,2 \text {, and } 3\end{array}$} \\
\hline & & & & \multicolumn{3}{|l|}{ stimulation site } \\
\hline & & & & $\begin{array}{l}1: 2.5 \mathrm{~cm} \\
\text { behind } \\
\text { bregma (SMA) }\end{array}$ & $\begin{array}{l}\text { 2: } 2 \mathrm{~cm} \text { behind } \\
\text { stimulation site } 1 \\
\text { (precentral gyrus) }\end{array}$ & $\begin{array}{l}\text { 3: } 4 \mathrm{~cm} \text { behind } \\
\text { stimulation site } 1 \\
\text { (postcentral gyrus) }\end{array}$ \\
\hline 1 & $59 / M$ & meningioma & frontal & $0.39 \mathrm{mV}$ & $0.38 \mathrm{mV}$ & $0.07 \mathrm{mV}$ \\
\hline 2 & $54 / \mathrm{M}$ & glioma & parietal & $0.20 \mathrm{mV}$ & $0.50 \mathrm{mV}$ & $0.44 \mathrm{mV}$ \\
\hline 3 & $64 / M$ & glioma & frontal & $0.28 \mathrm{mV}$ & $3.89 \mathrm{mV}$ & $0.30 \mathrm{mV}$ \\
\hline 4 & $26 / M$ & glioma & frontal & $0.03 \mathrm{mV}$ & $0.20 \mathrm{mV}$ & $0.07 \mathrm{mV}$ \\
\hline 5 & $75 / F$ & metastasis & parietal & $0.43 \mathrm{mV}$ & $1.14 \mathrm{mV}$ & $0.56 \mathrm{mV}$ \\
\hline 6 & $77 / M$ & meningioma & parietal & no CMAP & $6.12 \mathrm{mV}$ & $5.45 \mathrm{mV}$ \\
\hline 7 & $49 / \mathrm{F}$ & meningioma & parietal & no CMAP & $3.33 \mathrm{mV}$ & no CMAP \\
\hline 8 & $39 / M$ & glioma & frontal & $0.01 \mathrm{mV}$ & $5.27 \mathrm{mV}$ & no CMAP \\
\hline 9 & $52 / F$ & meningioma & frontal & minimal signal & $0.17 \mathrm{mV}$ & no CMAP \\
\hline 10 & $32 / M$ & glioma & frontal & no CMAP & minimal signal & no CMAP \\
\hline 11 & $39 / F$ & glioma & frontal & no CMAP & $0.9 \mathrm{mV}$ & no CMAP \\
\hline 12 & $61 / M$ & glioma & frontal & no CMAP & $0.05 \mathrm{mV}$ & no CMAP \\
\hline
\end{tabular}

(6.5 $\mathrm{cm}$ behind bregma) dorsal to the first stimulation site. The intraoperative motor threshold of each stimulation site was defined by stepwise increase of the stimulator output ( $10 \%$ steps, starting with $60 \%$ of the maximum stimulator output $(2.5 \mathrm{~T})$ ) before the investigation. According to the literature the motor threshold is lowest and the MEP amplitudes are highest if stimulation directly overlies the primary motor cortex. ${ }^{12}{ }^{13}$ Thus, the authors hypothesised that the site with the lowest motor threshold and/or the site that allows to obtain MEP of peak amplitudes localises the primary motor cortex. Accordingly, the lowest stimulation intensity, which allowed to elicit a motor response from at least one stimulation site, was applied during the motor cortex localising procedure. In our patients, this stimulation intensity ranged between $70 \%$ and $90 \%$ of the maximum stimulator output. If no MEP were obtainable at the three medial sites despite maximum stimulation intensity, stimulation was repeated in anteroposterior direction again more laterally (3 $\mathrm{cm}$ to $5 \mathrm{~cm}$ from the midline). At each site, the train of four stimuli was repeated at least once. As the authors in this feasability study aimed to merely localise the praecentral gyrus, no attempts were made to identify different cortical representation of the upper and lower limb muscles. Thus, the stimulation coil was exclusively moved in anteroposterior direction and not mediolaterally along the motor strip. During the whole investigation, the orientation of the coil (tangential to skull, the handle pointing strictly dorsally) was kept unchanged. The figure of eight coil, which induces a highly focal electrical field at the junction of the two loops, was used for motor cortex activation. The outer diameter of each loop of the figure of eight coil was $7 \mathrm{~cm}$.

Subdermal concentric needle electrodes were used for recording MEP. The active electrode was placed over the muscle belly, referenced to an electrode placed over the muscle tendon. The ground electrode was placed on the leg, proximal to the knee. ${ }^{14}$ As tumours could dislocate the cortical representation of upper and lower limb muscles in both anteroposterior and mediolateral direction, the authors believed that the muscles that will be activated by focused magnetic stimulation at the selected sites are not exactly predictable. In addition, stimulation at bordering sites where overlapping muscle representations occur, might elicit responses by several muscles. ${ }^{12}$ In consequence, the authors used recording electrodes in the contralateral abductor pollicis brevis, forearm flexor, biceps brachii, triceps brachii, anterior tibial, abductor hallucis, adductor longus, and quadriceps femoris muscles. The signal was amplified 2000 to 5000 times. The low cut off and high cut off filters were set at $30 \mathrm{~Hz}$ and $3000 \mathrm{~Hz}$. About 20 minutes were required for cortical stimulation and MEP recording. Each scalp stimulation site was matched with the underlying cortical anatomy using frameless stereotaxy.

\section{Frameless stereotaxy}

Frameless stereotaxy was performed with the EasyGuide Neurosystem (Philips Medical Systems, Best, Netherlands), which consists of a mobile workstation, an optical localising system with two infrared sensitive cameras positioned on a single camera stand and pointers with infrared light emitting diodes. External fiducials were placed on the patient's scalp and $\mathrm{Tl}$ weighted magnetic resonance (MR) imaging was performed. The data were transferred to the workstation to reconstruct an individual 3-D model of the patient's head and brain. The coordinates of the reconstructed 3-D model were correlated with the head position by touching the fiducials on the patient's skin with the pointer, which links the tip of the pointer with its representation on the screen. The system inaccuracy was tolerated if the root mean square error (RMSE), which compares the relation of the fiducial position on the MR images with the registered fiducials on the patient's head, was below $3.5 \mathrm{~mm}$. The skin position of the junction region of the figure of eight coil was related to the underlying gyral anatomy by stepwise virtual elongation of the pointer from the scalp to the cortical surface. As identification of the cortical anatomy on MR images was crucial for verification of the electrophysiological testing in this preliminary study, patients with grossly distorted anatomy, which made anatomical identification of sensorimotor cortex impossible, were excluded.

\section{RESULTS}

Stimulation was performed at a total of 42 sites (in two patients, maximum stimulation at the three initial sites failed to evoke a motor response). In all 12 patients, MEP contralateral to the stimulation and tumour site could be obtained by rTMS from at least one muscle, but the number of 
A

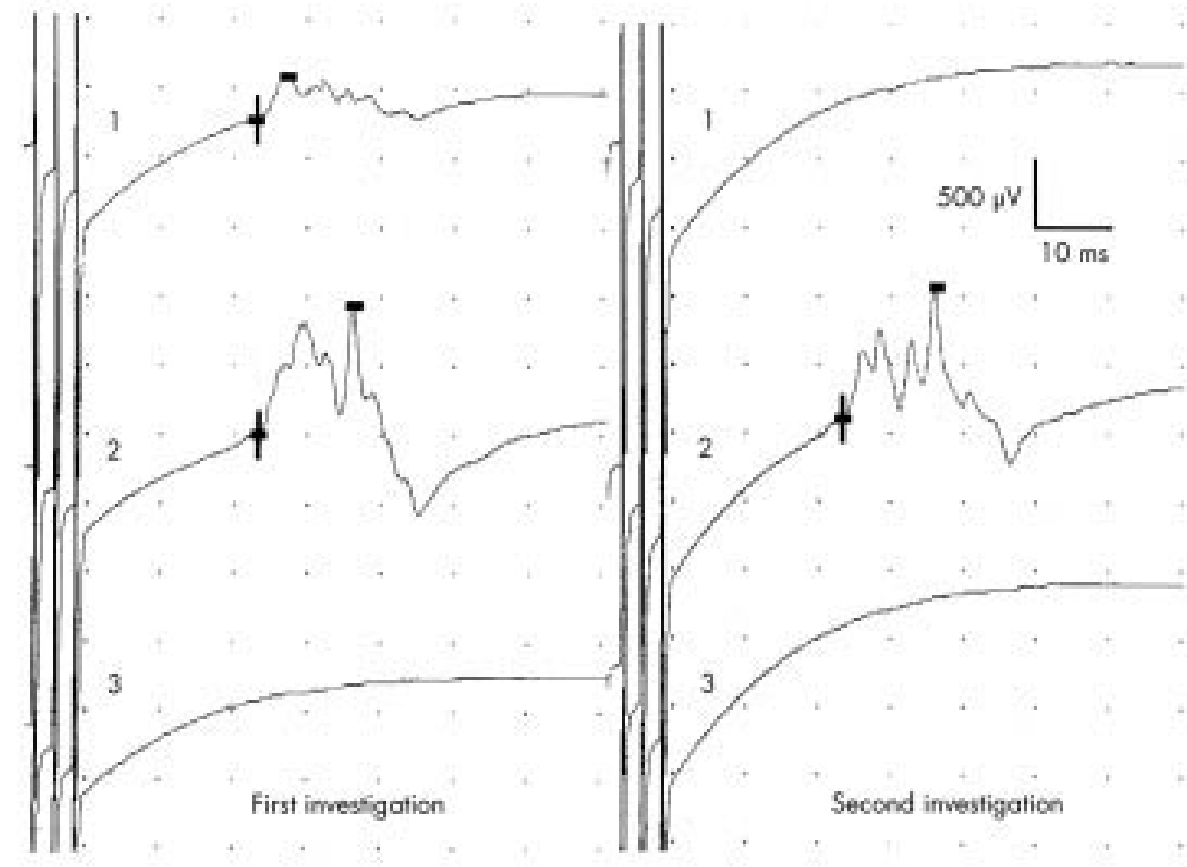

B

1

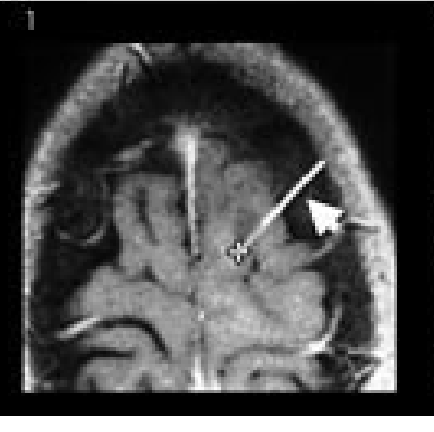

stimulation sites, which allowed to evoke MEP, varied. In 4 of 12 patients, reproducible MEP could be elicited only from the stimulation site, which was $4.5 \mathrm{~cm}$ behind the bregma ( fig 1). Virtual elongation of the pointer of the frameless stereotactic device indicated that this scalp stimulation site exactly overlaid the praecentral gyrus. In three patients, reproducible electromyographic responses could be obtained from two stimulation sites. As shown by neuronavigation, MEP with the maximal amplitude could be obtained from the stimulation site $4.5 \mathrm{~cm}$ behind bregma, which corresponded to the praecentral gyrus. In two patients, MEP with lower amplitudes could be elicited from the first stimulation site $(2.5 \mathrm{~cm}$ behind bregma), which overlied the supplementary motor area. In one patient, MEP with lower amplitudes were obtained following stimulation $6.5 \mathrm{~cm}$ behind bregma. This site corresponded to the postcentral gyrus. In the remaining five patients, MEP could be recorded from three stimulation sites. In four of the five patients, MEP with the highest amplitude could be obtained from stimulation site $2(4.5 \mathrm{~cm}$ behind bregma), which corresponded to the praecentral gyrus. In one patient, MEP with the highest amplitude were elicited after stimulation $2.5 \mathrm{~cm}$ behind bregma. Neuronavigation showed that this stimulation site overlied the supplementary motor area. In summary, either the stimulation site from which the peak amplitude could be obtained or the only site, which allowed to elicit evoked potentials, indicated the praecentral gyrus correctly in 11 of 12 patients (92\%) (table 1).
Figure 1 A 39 year old woman with a left low grade glioma in the anterior part of the superior frontal gyrus undergoing intraoperative localisation of the unexposed primary motor cortex with high frequency repetitive transcranial magnetic stimulation (rTMS). (A)

Electromyographic responses from the contralateral anterior tibial muscle after cortical stimulation at three stimulation sites (first stimulation site (1): $2.5 \mathrm{~cm}$ behind bregma close to midline; second stimulation site (2): 2 $\mathrm{cm}$ behind first stimulation site; third stimulation site (3): $4 \mathrm{~cm}$ behind first stimulation site). At each site, the train of four stimuli was repeated once (first investigation, second investigation). (B) Transfer of the three stimulation sites to the underlying cortical anatomy via virtual elongation of the pointer of a navigational system (arrow heads). No electromyographic responses were registered after stimulation of the postcentral gyrus (3). No reproducible electromyographic responses were obtained after stimulation of the superior frontal gyrus (supplementary motor area) (1). The praecentral gyrus (primary motor cortex) (2) could be identified by reproducible electromyographic responses of high amplitude. 
imaging, positron emission tomography, magnetencephalography, and dipole source analysis of somatosensory evoked potentials have been used for preoperative motor cortex identification. ${ }^{23-27}$ Our research group successfully used single focused magnetic cortical stimulation for motor cortex localisation in awake patients with brain tumours before surgery. ${ }^{28}$ However, independent of the mode of functional data collection, neuronavigation is always required for the transfer of the preoperatively collected information into the operative field. ${ }^{29}$ Drainage of cerebrospinal fluid and tumour debulking inevitably result in a certain shifting of the brain. In consequence, neuronavigation, which has to rely only on preoperatively obtained data, becomes an increasingly inaccurate tool during surgery. ${ }^{30}$ Thus, the surgeon could rely on the neuronavigationally transferred functional data only at the very beginning of the operation. For updating the preoperative image information, electrophysiological tests have been applied. Direct cortical electric stimulation and MEP recording as well as median nerve stimulation and localising the area of phase reversal of somatosensory evoked potentials allows to identify the praecentral gyrus and the central sulcus reliably during surgery. ${ }^{31}{ }^{32}$ As the stimulation respectively the recording electrode has to be placed onto the cortex, exposure of the motor strip in vicinity to the tumour is mandatory. ${ }^{33}$ Thus, skull and dural openings larger than for mere tumour removal are required for intraoperative motor cortex identification. This counteracts the ongoing efforts to minimise the surgical approaches.

On the search for an intraoperative brain shift independent localising tool, which supports the concept of minimal surgical invasiveness, the authors brought together their experiences with focused TMS in awake patients and rTMS in anaesthesised humans. ${ }^{128}$ The authors show in this pilot study, that focused rTMS is able to determine the localisation of the primary motor cortex intraoperatively with high accuracy and sensitivity. In contrast with electrical stimulation of the cortex and somatosensory evoked potentials phase reversal, exposure of the motor cortex is not required. In analogy to mapping studies in awake humans, stimulation of the primary motor cortex is predominantly indicated by MEP of peak amplitude. It is in accordance with the electrophysiological literature, that MEP of lower amplitude sometimes could be obtained after stimulation of the supplementary motor area and the postcentral gyrus.

\section{CONCLUSION}

Focused rTMS can localise the primary motor cortex during brain tumour surgery with high accuracy and sensitivity. In contrast with the most commonly used localising techniques, direct electrical cortical stimulation and somatosensory evoked potentials phase reversal, exposure of the brain surface at risk is not required, which supports the concept of minimalised invasiveness of the surgical intervention. Preoperative repetitive or single TMS for motor cortex identification could be useful for rapid intraoperative definition of the optimal initial stimulation site before substantial tumour removal and cerebrospinal fluid drainage. However, preoperative TMS could not be a substitute for intraoperative TMS as brain shift results in a progressive incongruence of the findings. With refinements of the bulky coil design provided, focused rTMS can become a useful localising tool for patients, in whom minimalised access to the lesion is planned or in whom excessive shifting of the brain dislocates the motor cortex beneath the opening of the dura and the skull.

\section{ACKNOWLEDGEMENT}

We thank Ferhan Üstener for assistance during the intraoperative electrophysiological testing. The work was presented in parts at the 50th annual meeting of The German Society of Neurological Surgeons, Munich, June 1999.

\section{Authors' affiliations}

V Rohde, L Mayfrank, M Weinzierl, J M Gilsbach, Department of

Neurosurgery, Aachen University, Germany

T Krings, Department of Neuroradiology, Aachen University

Funding: the work was supported by grants of the Stiftung

Tumorforschung Kopf-Hals given to the first author.

Competing interests: none declared.

\section{REFERENCES}

1 Barker AT, Jalinous R, Freeston IL. Non-invasive magnetic stimulation of human motor cortex. Lancet 1985;i:1106-7.

2 Day BL, Thompson PD, Dick JP, et al. Different sites of action of electrical and magnetic stimulation of the human brain. Neurosci Lett 1987;75:101-6.

3 Burke D, Hicks R, Gandevia SC, et al. Direct comparison of corticospinal volleys in human subjects to transcranial magnetic and electrical stimulation. J Physiol 1993:470:383-93.

4 Barker AT, Freeston IL, Jabinous R, et al. Clinical evaluation of conduction time measurements in central motor pathways using magnetic stimulation of human brain. Lancet 1986;i:1325-6.

5 Cowan JM, Rothwell JC, Dick JP, et al. Abnormalities in central motor pathway conduction in multiple sclerosis. Lancet 1984;ii:304-7.

6 Hallett $M$. Transcranial magnetic stimulation: a useful tool for clinical neurophysiology. Ann Neurol 1996;40:344-5.

7 Hess CW, Mills KR, Murray NM, et al. Magnetic brain stimulation: central motor conduction studies in multiple Sclerosis. Ann Neurol 1987;22:744-52.

8 Ingram DA, Thompson AN, Swash M. Central motor conduction in multiple sclerosis: evaluation of abnormalities revealed by transcutaneous magnetic stimulation of the brain. J Neurol Neurosurg Psychiatry 1988:51:487-94.

9 Gugino LD, Aglio LS, Potts G, et al. Perioperative use of transcranial magnetic stimulation. Techn Neurosurg 2001;7:33-51.

10 Rohde V, Krombach GA, van Oosterhout A, et al. Intraoperative monitoring of the spinal motor pathways using repetitive transcranial magnetic motor cortex stimulation. [Abstract]. Zentralb/ Neurochir 1998; suppl: 141.

11 Rohde V. Beiträge zur Lokalisation und Funktionsüberprüfung des kortikospinalen motorischen Systems mittels repetitiver Magnetstimulation vor und während neurochirurgischer Eingriffe. [Thesis]. Aachen: Medical Faculty of the Technical University Aachen, Gemany: 1999.

12 Amassian VE, Cracco RQ, Maccabee PJ, et al. Matching focal and non-focal magnetic coil stimulation to properties of human nervous system: mapping motor unit fields in motor cortex contrasted with altering sequential digit movements by premotor-SMA stimulation. Electroencephal Clin Neurophysiol 1991; suppl 43:3-28.

13 Krings T, Buchbinder BR, Butler WE, et al. Stereotactic transcranial magnetic stimulation: Correlation with direct electrical stimulation. Neurosurgery 1997;41:1319-26.

14 Kalkman CJ, Ubags LH, Been HD, et al. Improved amplitude of myogenic motor evoked responses after paired transcranial electrical stimulation during sufentanil/nitrous oxide anesthesia. Anesthesiology 1995;83:270-6.

15 Pechstein U, Cedzich C, Nadstawek J, et al. Transcranial high-frequency repetitive electrical stimulation for recording myogenic motor evoked potentials with the patient under general anesthesia. Neurosurgery 1995;39:335-44.

16 Cohen LG, Roth BJ, Nilsson J, et al. Effects of coil design on delivery of focal magnetic stimulation. Technical considerations. Electroencephalog Clin Neurophysiol 1990;75:350-7.

17 Boroojerdi B, Foltys $\mathrm{H}$, Krings T, et al. Localization of the motor hand area using trasncranial magnetic stimulation and functional magnetic resonance imaging. Clin Neurophysiol 1999;1 10:699-704.

18 Mortifee $\mathbf{P}$, Stewart $H$, Schulzer M, et al. Reliability of transcranial magnetic stimultion for mapping the human cortex. Electroencephal Clin Neurophysiol 1994;93:131-7.

19 Levy WJ, Amassian VE, Schmid UD, et al. Mapping of the motor gyral sites noninvasively by transcranial magnetic stimulation in normal subjects and patients. Electroencephal Clin Neurophysiol 1991; suppl 43:51-75.

20 Taniguchi $\mathbf{M}$, Nadstawek J, Langenbach U, et al. Effects of four intravenous anesthetic agents on motor evoked potentials elicited by magnetic transcranial stimulation. Neurosurgery 1993;33:407-15

21 Watt JW, Fraser MH, Soni BM, et al. Total i.v. anaesthesia for transcranial magnetic evoked potential spinal cord monitoring. $\mathrm{Br} J$ Anaesth 1996:76:870-1.

22 Katayama Y, Tsubokawaq T, Maejina S, et al. Corticospinal direct responses in humans: identification of the motor cortex during intracranial surgery under general anaesthesia. J Neurol Neurosurg Psychiatry 1988;51:50-9.

23 Berger MS, Cohen WA, Ojeman GA. Correlation of motor cortex brain mapping data with magnetic resonance imaging. J Neurosurg 1990;72:383-7.

24 Bittar RG, Olivier A, Sadikot AF, et al. Presurgical motor and somatosensory cortex mapping with functional magnetic resonance imaging and positron emission tomography. J Neurosurg 1999;91:915-21. 
25 Buchner $\mathbf{H}$, Adams L, Knepper A, et al. Preoperative localization of the central sulcus by dipole source analysis of early somatosensory evoked potentials and three-dimensional magnetic resonance imaging. $J$ Neurosurg 1994;80:849-56.

26 Ganslandt O, Fahlbusch R, Nimsky $C$, et al. Functional neuronavigation with magnetoencephalography: outcome in 50 patients with lesions around the motor cortex. J Neurosurg 1999;91:73-9.

27 Krings T, Reinges MHT, Erberich S, et al. Functional MRI for presurgical planning: problems, artefacts, and solution strategies. J Neurol Neurosurg Psychiatry 2001;70:749-60.

28 Krings T, Foltys H, Reinges MHT, et al. Navigated transcranial magnetic stimulation for presurgical planning - correlation with functional MRI. Minim Invas Neurosurg 2001;44:234-9.

29 Reinges MHT, Krings T, Nguyen $\mathrm{HH}$, et al. Virtual pointer projection of the central sulcus to the outside of the skull using frameless neuronavigation-accuracy and applications. Acta Neurochir 2000; 142:1385-90.

30 Roberts DW, Hartov A, Kennedy FE, et al. Intraoperative brain shift and deformation: a quantative analysis of cortical displacement in 28 cases. Neurosurgery 1998;43:749-60.

31 Cedzich C, Taniguchi M, Schafer S, et al. Somatosensory evoked potential phase reversal and direct motor cortex stimulation during surgery in and around the central region. Neurosurgery 1996;38:962-70

32 Kombos T, Suess O, Funk T, et al. Intra-operative mapping of the motor cortex during surgery in and around the motor cortex. Acta Neurochir 2000;142:263-8.

33 Silbergeld DL. A new device for cortical stimulation mapping of surgically unexposed cortex. J Neurosurg 1993;79:612-14.

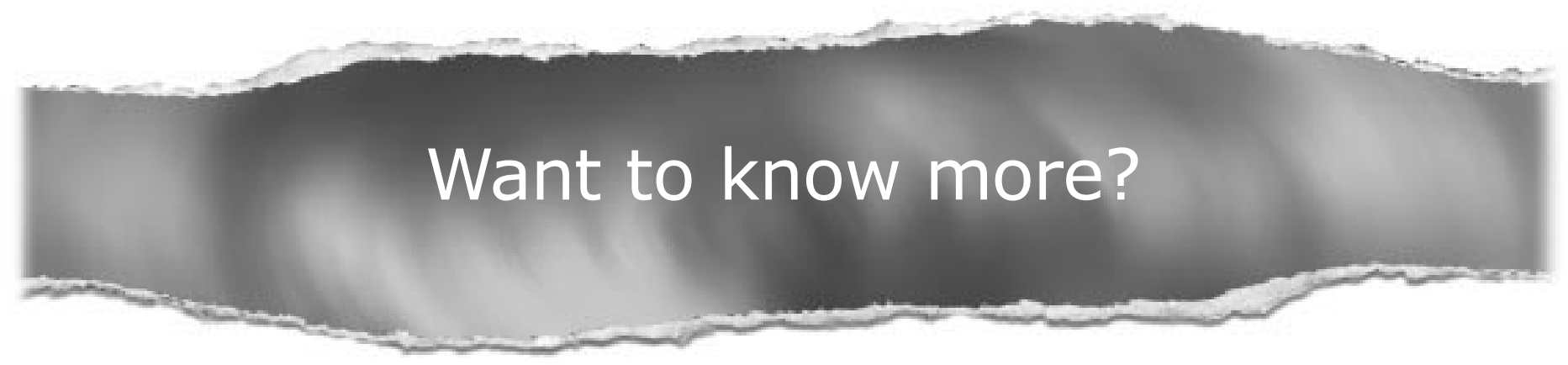

Data supplements

Limited space in printed journals means that interesting data and other material are often edited out of articles; however, limitless cyberspace means that we can include this information online.

Look out for additional tables, references, illustrations.

www.jnnp.com 